\title{
Structural and fractal characteristics of biofilm attached on the surfaces of aquatic plants and gravels in the rivers and lakes reusing reclaimed wastewater
}

\author{
Liang Mingchao $\cdot$ Wang Tianzhi $\cdot$ Li Yunkai · \\ Yang Peiling $\cdot$ Liu Chengcheng $\cdot$ Li Pengxiang • \\ Zhao Wei
}

Received: 22 September 2011/Accepted: 23 January 2013/Published online: 23 February 2013

(C) Springer-Verlag Berlin Heidelberg 2013

\begin{abstract}
Reusing reclaimed wastewater from lakes has become one of the most effective measures to relieve the urban ecological crisis. However, reclaimed wastewater still contains large amounts of nutrient salts, trace organic pollutants, suspended solid particles and microorganisms, which may significantly affect the aquatic ecosystems. The health of aquatic ecosystems can be directly and effectively monitored by evaluating the biofilms in them, because the structures of biofilms are directly affected by multiple environmental factors. Therefore, it is important to study the structures of biofilms attached on multiple medium surfaces in river-lake systems that contain reclaimed wastewater. In this study, the paper applied scanning electron microscope (SEM) technology and fractal theory to quantitatively describe the structural characteristics of biofilms attached on the medium surfaces of aquatic plants and gravels in the Lianshi Lake of Beijing Yongding River and other two kinds of reclaimed water of the river-lakes, whose sewage treatment processes were the combined process of deposit and sand filtration and UF membrane filtration, plus anaerobic-anoxic-oxic process, respectively. The paper found that these two types of biofilms were typical porous media and their basic skeletons were mainly
\end{abstract}

L. Mingchao, W. Tianzhi and L. Yunkai equally contributed to this paper.

L. Mingchao · W. Tianzhi · L. Yunkai · Y. Peiling ·

L. Chengcheng $\cdot$ L. Pengxiang $\cdot$ Z. Wei

Center for Agricultural Water Research in China,

China Agricultural University, Beijing 100083, China

L. Yunkai $(\bowtie)$

State Key Laboratory of Urban and Regional Ecology, Research Center for Eco-Environmental Sciences, Chinese Academy of Sciences, Beijing 100085, China

e-mail: liyunkai@126.com composed of inorganic particles, microorganisms, and algae. Furthermore, most areas between the particles were filled with extracellular polymers (EPS) secreted by bacteria. At the same time, these biofilms showed obvious fractal and multifractal characteristics, but the fractal dimensions alone failed to effectively describe the complexity of biofilm structures. The multifractal spectra were able to quantitatively characterize the biofilms' heterogeneity. In addition, the number of microorganism species, the quantity and the heterogeneity of aquatic plants' surface biofilms were all higher than those of gravel surface biofilms, most likely due to the effects of light. In addition, the heterogeneity of biofilms in reclaimed water treated by the combined process of deposit and sand filtration and UF membrane filtration plus anaerobic-anoxic-oxic process was higher than that of biofilms in reclaimed water treated by traditionally activated sludge process (Lianshi Lake's water). Besides, the non-uniformity of biofilms in reclaimed water treated by combined process of deposit and sand filtration was higher than that of biofilms in reclaimed water treated by UF membrane filtration plus anaerobic-anoxic-oxic process.

Keywords Biofilm $\cdot$ Surface structure $\cdot$ Reclaimed wastewater $\cdot$ Fractal $\cdot$ River and lake

\section{Introduction}

The microorganisms, including bacteria, fungi, protozoa and metazoan, are important components of the aquatic ecosystems with large quantity, great variety and fast breeding. They play an important role in pollution removal, material recycling, migration, transformation and ecosystems' restoration in water and sediments. Microbial growth 
and survival have become one of the key lake biogeochemical cycles of lake systems. Most natural microorganisms are not free in the growth environment, and about $90 \%$ of the microorganisms are attached to some solid surfaces in the form of biofilm (Costerton et al. 1999). Biofilms can be used to directly and effectively monitor and evaluate the health of aquatic ecosystems, because they reflect the overall performance of microbial communities' long-term evolution.

Biofilm has attracted much attention in the engineering fields, such as sewage treatment (Picioreanu et al. 2001), water supply and drainage (Percival et al. 1998). Indeed, the components of biofilms have high adsorption capacity for contaminants (Reichert and Wanner 1997; Schorer and Eicele 1997; Winpenny 1996). The agglomeration, adsorption and degradation of pollutants reflect the physical, chemical and biological purification process, which play an important role in self-purification process (Sergi et al. 2002). However, due to the complexity of natural water systems, there are only very limited studies conducted on biofilms characteristics in rivers (Qin 2008), lakes (Dong et al. 2005), wetlands ( $\operatorname{Li} 2005$ ) and oceans (Baty 1996). And the major method in these studies using artificial inert matrices, and in situ sampling has been lacking. Reclaimed wastewater has been applied to reduce the ecological crisis in cities (Fan and Lv 2005; Juanico and Friedler 1999; Huang and Wu 2008), which makes it an attractive system to study biofilms. Although reclaimed wastewater meets emission standards, it still contains a lot of nutritional salts, trace organics, suspended solid particles and microorganisms, which may make the characteristics of biofilms in reclaimed wastewater significantly different from those in natural water. Unfortunately, no related studies have been reported.

The structural characteristics of biofilms include the micro-features, such as the membrane surface roughness and porosity. Many factors, including hydraulicity, water quality, and temperature, affect its features (Rao 1997; Tatlor T1997), thus the biofilms in different aquatic systems have different structural characteristics. The development of fine microscopy, such as SEM, confocal laser scanning microscopy (CLSM) and 3-dimensional scanning white-light interference profilometer (3D SWIP), has provided effective tools to study the complex surface structures of biofilms (Baloch et al. 2008; Wang 2003; Li 2011). Fractal theory, first put forward by Mandelbrot in 1973, is a tool to describe complicated and nonlinear phenomenon in nature (Mandelbrot et al. 1984). It supplies a new idea and a powerful tool to deal with irregular geometric and disordered phenomena. The combination of fine microscopy techniques and the fractal theory may become a highly effective novel method to quantify the surface characteristics of biofilms.
The study applied SEM and fractal theory to quantify the structural characteristics of biofilms that were attached to aquatic plants and gravels' surfaces in the rivers and lakes reusing reclaimed water. The study provides a theoretical basis to assess the purification capacity and health of aquatic systems.

\section{Materials and methods}

Sampling locations

The biofilms attached on the surfaces of aquatic plants and gravels were collected from Lianshi Lake and other two kinds of reclaimed water of river-lakes, whose sewage treatment processes were the combined process of deposit and sand filtration and UF membrane filtration, plus the anaerobic-anoxic-oxic process, respectively. The sampling locations in this study were shown in Fig. 1 and Table 1. The sampling points for the biofilms were all in the center of lakes or rivers. All gravel biofilms' samples were collected at the bottom of lakes or rivers, all aquatic plants biofilms samples were taken from the distance of five meters above the ground water. Meanwhile, the water quality test was based on water and exhausted water monitoring analysis method (Wei Fusheng 2002). Each $500 \mathrm{ml}$ water sample was kept at $-4^{\circ}$ constant temperature (Table 2).

Biofilm sample collection, preparation and SEM scanning

Two kinds of biofilm samples were collected at each sampling location. The biofilm samples of aquatic plants and gravels' surfaces were collected from three different locations where aquatic plants grew exuberantly in Lianshi Lake. The samples were labeled $\operatorname{SLLP}_{\mathrm{A}}, \operatorname{SLLP}_{\mathrm{B}}$ and SLLP $_{C}$, respectively. The gravels were collected from the same three locations, sealed in bags and labeled as SLLS A $_{\text {, }}$ $\mathrm{SLLS}_{\mathrm{B}}$ and SLLS $\mathrm{C}$, respectively. All samples were quickly transported to the laboratory and preserved in the refrigerator.

The biofilms attached on the aquatic plants and gravels' surfaces were first cut into $0.6 \times 0.6 \mathrm{~cm}$ squares. The biofilm pieces were first fixed in $2.5 \%$ glutaraldehyde solution, followed by a rinse with $0.1 \mathrm{M}$ sodium phosphate buffer solution three times (15 min each). A second fixation of $3 \mathrm{~h}$ was given to the samples with $1 \% \mathrm{O}_{\mathrm{s}} \mathrm{O}_{4}$ solution, followed by the same rinse procedure. They were then dehydrated with 30, 50, 70, 85 and $95 \%$ ethanol once for $15 \mathrm{~min}$ for each concentration, followed by three times of $100 \%$ ethanol for $15 \mathrm{~min}$. The dehydrated samples were dried with BAL-TEC CPD030 by $\mathrm{CO}_{2}$ critical point drying 
Table 1 Sampling locations and number

\begin{tabular}{|c|c|c|c|c|c|c|c|c|}
\hline $\begin{array}{l}\text { Water } \\
\text { body type }\end{array}$ & Treatment process & $\begin{array}{l}\text { Recharge water } \\
\text { source }\end{array}$ & $\begin{array}{l}\text { Names of river and } \\
\text { lake }\end{array}$ & Area $\left(\mathrm{m}^{2}\right)$ & $\begin{array}{l}\text { Matrix } \\
\text { type }\end{array}$ & Number & Discharge & GPS \\
\hline \multirow[t]{5}{*}{$\begin{array}{l}\text { Reclaimed } \\
\text { water }\end{array}$} & $\begin{array}{l}\text { Traditionally-activated } \\
\text { sludge process }\end{array}$ & $\begin{array}{l}\text { Zhongmensigou } \\
\text { Reclaimed } \\
\text { water works }\end{array}$ & $\begin{array}{l}\text { Yongdinghe } \\
\text { Lianshi Lake } \\
\text { (SLL) }\end{array}$ & $10^{6}$ & $\begin{array}{l}\text { Gravels } \\
\text { Aquatic } \\
\text { Plants }\end{array}$ & $\begin{array}{l}\text { SLLS } \\
\text { SLLP }\end{array}$ & $10^{6} \mathrm{~m}^{3}$ & $\begin{array}{l}\mathrm{N} 39^{\circ} 56^{\prime} \\
\mathrm{E} 116^{\circ} 06^{\prime}\end{array}$ \\
\hline & \multirow[t]{2}{*}{$\begin{array}{l}\text { Deposit and sand } \\
\text { filtration process }\end{array}$} & \multirow[t]{2}{*}{$\begin{array}{l}\text { Reclaimed } \\
\text { water works }\end{array}$} & Bahe (RJR) & $158.4 \times 10^{6}$ & $\begin{array}{l}\text { Gravels } \\
\text { Aquatic } \\
\text { Plants }\end{array}$ & $\begin{array}{l}\text { RJRS } \\
\text { RJRP }\end{array}$ & $1.2 \times 10^{8} \mathrm{~m}^{3}$ & $\begin{array}{l}\text { N39 } 58^{\prime} \\
\text { E116 } 33^{\prime}\end{array}$ \\
\hline & & & $\begin{array}{l}\text { Honglingjin Park } \\
\text { Lake (RJL) }\end{array}$ & $0.16 \times 10^{6}$ & $\begin{array}{l}\text { Gravels } \\
\text { Aquatic } \\
\text { Plants }\end{array}$ & $\begin{array}{l}\text { RJLS } \\
\text { RJLP }\end{array}$ & $0.2 \times 10^{6} \mathrm{~m}^{3}$ & $\begin{array}{l}\mathrm{N} 39^{\circ} 55^{\prime} \\
\mathrm{E} 116^{\circ} 29^{\prime}\end{array}$ \\
\hline & \multirow[t]{2}{*}{$\begin{array}{l}\text { Ultrafiltration ozone } \\
\text { process }\left(\mathrm{A}^{2} / \mathrm{O}\right)\end{array}$} & \multirow[t]{2}{*}{$\begin{array}{l}\text { Reclaimed } \\
\text { water works }\end{array}$} & Qinghe (RQR) & $50.2 \times 10^{6}$ & $\begin{array}{c}\text { Gravels } \\
\text { Aquatic } \\
\text { Plants }\end{array}$ & $\begin{array}{l}\text { RQRS } \\
\text { RQRP }\end{array}$ & $5.2 \times 10^{8} \mathrm{~m}^{3}$ & $\begin{array}{l}\mathrm{N} 40^{\circ} 01^{\prime} \\
\mathrm{E} 116^{\circ} 21^{\prime}\end{array}$ \\
\hline & & & $\begin{array}{l}\text { Aoyun Lake } \\
\text { (RQL) }\end{array}$ & $1.2 \times 10^{6}$ & $\begin{array}{c}\text { Gravels } \\
\text { Aquatic } \\
\text { Plants }\end{array}$ & $\begin{array}{l}\text { RQLS } \\
\text { RQLP }\end{array}$ & $1.9 \times 10^{6} \mathrm{~m}^{2}$ & $\begin{array}{l}\mathrm{N} 40^{\circ} 00^{\prime} \\
\mathrm{E} 116^{\circ} 24^{\prime}\end{array}$ \\
\hline
\end{tabular}

$S L$ stands for Yongdinghe Lianshi Lake, $R J$ stands for combinatorial process of deposit and sand filtration in Jiuxianqiao Reclaimed Water Works, $R Q$ stands for ultrafiltration ozone process $\left(\mathrm{A}^{2} / \mathrm{O}\right)$ in Qinghe Reclaimed Water Works, $R$ stands for rivers, $L$ stands for lakes, $S$ stands for Gravels; and $P$ stands for aquatic plants

Table 2 Test results of water quality $(\mathrm{mg} / \mathrm{L})$

\begin{tabular}{lllllll}
\hline Number & SLL & RJH & RJL & RQR & RQL & Method \\
\hline $\mathrm{NH}_{4}{ }^{+}-\mathrm{N}$ & 0.39 & 3.24 & 0.81 & 15.8 & 0.33 & Nessler's colorimetric method \\
$\mathrm{NO}_{3}^{-}$ & 2.71 & 11.6 & 0.88 & 9.07 & 3.78 & Ion chromatography \\
$\mathrm{PO}_{4}{ }^{3-}$ & 0.02 & 0.96 & 0.24 & 16.1 & 0.34 & \\
$\mathrm{SO}_{4}{ }^{2-}$ & 247 & 100 & 78.7 & 93.2 & 92.9 & \\
$\mathrm{HCO}_{3}{ }^{-}$ & 125 & 344 & 163 & 298 & 110 & \\
$\mathrm{TN}$ & 4.58 & 16.2 & 1.8 & 28.6 & 5.46 & \\
$\mathrm{TP}$ & 0.11 & 0.38 & 0.22 & 0.82 & 0.17 & \\
$\mathrm{BOD}$ & 6.6 & 11.8 & 8.8 & 8.2 & 3.9 & Dilution inoculation method \\
$\mathrm{COD}$ & 29.7 & 47.7 & 38.2 & 36.2 & 19.3 & Potassium dichromate Method \\
$\mathrm{SP}$ & 0.05 & 0.32 & 0.08 & 0.5 & 0.14 & Gas chromatographic method \\
$\mathrm{Ca}^{2+}$ & 43.7 & 75 & 29.1 & 63.6 & 36.8 & Flame atomic absorption spectrophotometry \\
$\mathrm{Mg}^{2+}$ & 34 & 31.7 & 20.8 & 21.1 & 22 & Glass electrodes method \\
$\mathrm{pH}$ & 7.92 & 7.54 & 7.86 & 7.21 & 9.34 & \\
\hline
\end{tabular}

method, before going through the gold sputtering step with ion sputter BAL-TEC SCD005.

Fractal theory, multifractal, and parameter calculation

\section{Fractal and fractal dimension of surface structure}

Fractal dimension quantifies the complex degree of fractals, which makes it the characteristic parameter of fractals. The fractal dimension of biofilm surface structure was analyzed with the Slit Island Method that calculates the fractal dimensions according to the measured relationships, which was pointed out by Mandelbrot as follows (Mandelbrot et al. 1984):

$\alpha_{D}(\varepsilon)=\frac{L^{\frac{1}{D}}(\varepsilon)}{A^{\frac{1}{2}}(\varepsilon)}$

where $L$ is porous perimeter, $A$ is pore area, $D$ is fractal dimension, $\varepsilon=\eta / L_{0}$ (where $\eta$ is absolute measurement scale, $L_{0}$ is perimeter of original picture). When $\eta$ is invariable, $\alpha_{D}(\varepsilon)$ is constant $\left(\alpha_{D}(\varepsilon)\right.$ the picture associates 
Fig. 1 Sampling locations, Notes: Labe (1) is Lianshi Lake, Labe (2) is Bahe River, Labe (3) is Honglingjin Park Lake, Labe (4) is Qinghe River, Labe $f$ is Aoyun Lake

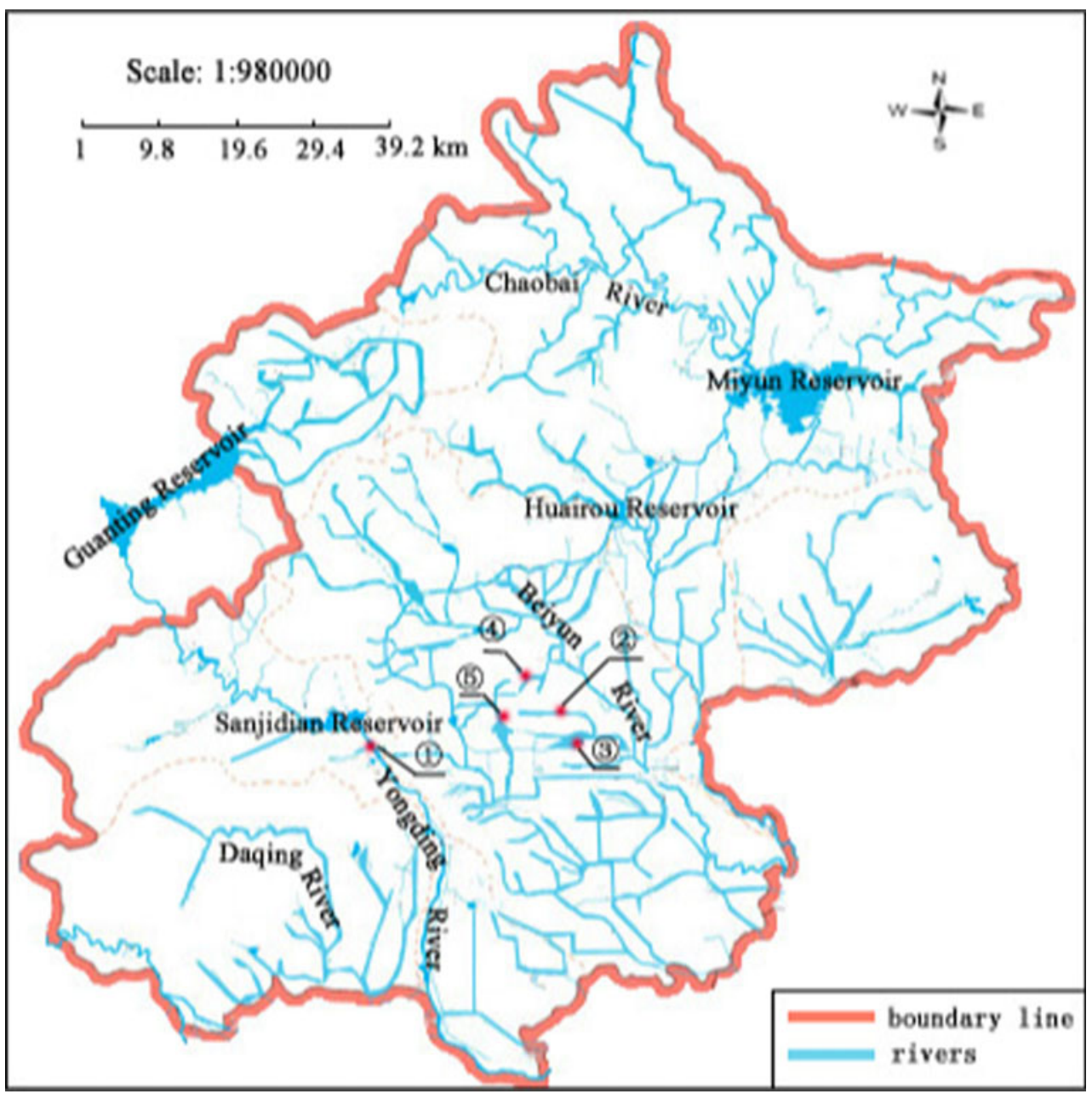

with selected scales but not with the size of picture). Use logarithmic transformation of Eq:

$\lg L(\varepsilon)=D \lg \alpha_{D}(\varepsilon)+\frac{D}{2} \lg A(\varepsilon)=C+\frac{D}{2} \lg A(\varepsilon)$

where $C$ is a constant. The perimeter and area of each pore were measured with SEM images. From the graph of $\log$ ( $L$, perimeter) versus $\log (A$, area), fractal dimension $D$ is equal to two times of the slope of the best fitting line in the graph.

\section{Multifractal and the calculation of multifractal singular spectrum}

Multifractal is defined as a set that consists of an infinite number of scale-free indexes in fractal structure. It can use a spectrum function to describe the probability distribution of geometric figures or physical quantity in space, and to describe certain measurements of self-similarity or statistical self-similarity. It can also reveal special structures, behaviors and characteristics that are caused by different local conditions at different levels, in order to study the characteristics as a whole of the local system and to explain the distributing rules of probability measures of the characteristic parameters by the method of statistical physics.

Multifractal describes a measurement that is defined in a certain area or volume and can decompose the defined domain into a series of subdomains in space, according to the singularity of this measurement, and every subdomain constitutes a single fractal. Multifractals have not only fractal dimensions but also respective singularity of every measurement. Multifractal cannot be described by one parameter because of its heterogeneity, and multifractal spectrum is the main parameter to quantify the heterogeneity of multifractals, which can be expressed by the languages of $\alpha \sim f(\alpha)$ and $q \sim D(q)$. The relationship between the two languages can be acquired by the Legendre Transform.

Assume that a set of different grids with square cells of size $\varepsilon$ is superimposed on the whole study field. The total number of grids is $N(\varepsilon)$. The measurement of number $i$ grid is $N(\varepsilon)$. The sum of the measurements of fractal sets is $N_{t}$, thus the probability measure of number $i$ grid is calculated by: 
$\mu_{i}(\varepsilon)=\frac{N_{i}(\varepsilon)}{N_{t}}$

In statistical physics, a partition function of $\chi_{q}(\varepsilon)=$ $\sum_{i=1}^{N(\varepsilon)} \mu_{i}(\varepsilon)^{q}$ is used. In scale-free region, the scaling relation of $\chi_{q}(\varepsilon)$ is defined as the following:

$\chi_{q}(\varepsilon) \propto \varepsilon^{\tau(q)}$

where $\tau(q)$ is the mass exponent of order $q$. The value of $\tau(q)$ is estimated according to the best fitting line of the best fitting line. The general fractal dimension $D(q)$ of the biofilm's surface characteristics is:

$D(q)=\frac{\tau(q)}{(q-1)}=\lim _{\varepsilon \rightarrow 0} \frac{1}{q-1} \frac{\log \left[\sum_{i=1}^{N(\varepsilon)} \mu_{i}(\varepsilon)^{q}\right]}{\log \varepsilon}(q \neq 1)$

$D_{1}=\lim _{\varepsilon \rightarrow 0} \frac{\sum_{i=1}^{N(\varepsilon)} \mu_{i}(\varepsilon) \log \mu_{i}(\varepsilon)}{\log \varepsilon} \quad(q=1)$

when $q=0,1,2, D(q)$ corresponds to fractal capacity dimension, information dimension and correlation dimension, respectively (Posadas et al. 2003). The bigger the slope of $q \sim D(q)$ is, the larger the range of $D(q)$ will be, indicating wider distributing range of the fractal structure's different singularity strengths. It also demonstrates increased heterogeneity and complexity of the measured physical parameters.

Through Legendre transform, the relationships among $\alpha$, $f(\alpha)$ and $\tau(q)$ are acquired as follows:

$\alpha(q)=\frac{\partial}{\partial q} \tau(q) f(\alpha(q))=q \alpha(q)-\tau(q)$

Based on (7), $q \sim D(q)$ and $\alpha \sim f(\alpha)$ are equivalent in describing multifractal; the subsets of different exponents can be discerned by changing the iterative order $\mathrm{q}$. Therefore, the paper only used $\alpha \sim f(\alpha)$ multifractal singular spectrum to characterize the heterogeneity of biofilm's surface structures.

\section{Results and analysis}

Acquisition of SEM images and qualitative characterization of biofilms

Firstly, the structures of biofilms attached on the surfaces of aquatic plants and gravels in Lianshi Lake were analyzed by SEM (Figs. 2, 3). The SLLP Sample and SLLS $_{\mathrm{A}}$ sample were randomly selected to be shown at different enlargement rates $(2,000 \times, 5,000 \times, 8,000 \times$ and $1,0000 \times)$, and all other Lianshi Lake water samples' images were shown at $5,000 \times$. The results show that the observation of the biofilm structure is the best at $5,000 \times$, and all other reclaimed wastewater sample images were shown at $5,000 \times$. The results are shown in Fig. 4 and 5. A few pores with different diameters were observed on the biofilm surfaces, and the biofilms showed as typical porous media. Biofilms surface adsorbed a large amount of particles, including inorganic particles, microorganisms (mainly cocci, bacillus and other forms of bacteria), and algae. The pores between particles were filled with EPS, a sticky substance secreted by bacteria, which linked the microbial communities and other components to form the complex and stable filamentous or reticular structures.

The structures of these two types of biofilms were significantly different (Figs. 2, 3, 4, 5): the biofilms of gravels were denser than those of aquatic plant; the adsorption capacity of gavel surface biofilms was lower than that of aquatic plants; and the number of adsorbed material species of gravel surface biofilm was also smaller. In addition, a few algae species were observed on the aquatic plant surface biofilm, but the gravel surfaces biofilm had almost none.

Fractal characteristics of biofilm surface structures

After binary conversion, the SEM images of Figs. 2, 3, 4, 5 were analyzed with software Image-pro Plus 6.0 to obtain the pore area and perimeter of every surface. According to Eq. 2 , in the graph of $\lg \mathrm{A} \sim \operatorname{lgL}$, the data were analyzed by regression analysis, and the fractal dimension of surface structure of biofilm pores was determined as two times of the slope of the best fitting line. As shown in Figs. 6 and 7 (the example of Lianshi Lake) and Table 3, logs A $\sim$ L of each sample had a fairly good linear correlation $\left(R^{2}\right.$ were all above 0.95), indicating the biofilm surfaces of both sources had obvious fractal characteristics. Furthermore, the fractal dimensions of $\operatorname{SLLP}_{\mathrm{C}}$ sample with the four observing scales $(2,000 \times, 5,000 \times, 8,000 \times$ and $10,000 \times$ enlargement ratios) were $1.44,1.46,1.44$, and 1.44 , respectively with only small differences $(<1.4 \%)$. The fractal dimensions of SLLS $\mathrm{A}_{\mathrm{A}}$ sample with four observation scales $(2,000 \times, 5,000 \times, 8,000 \times$ and $10,000 \times$ enlargement ratios) were $1.44,1.46,1.50$, and 1.48 , respectively, also with only small differences $(<4.2 \%)$. These obvious scale invariances verified the fractal characteristics of biofilms from both sources.

In Lianshi Lake water, the average fractal dimensions of biofilms attached on surfaces of two media were 1.45 and 1.47 with the enlargement ratio of $5,000 \times$, the later one was a little higher, but the difference was within $0.5 \%$ (Table 3). The fractal dimensions of the three aquatic plant samples with the enlargement ratio of $5,000 \times$ were 1.44 , 1.48 and 1.44 , respectively, while the fractal dimensions of the gravel samples with the same ratio were $1.46,1.48$ and 
Fig. 2 SEM images of biofilms on aquatic plant in Lianshi Lake, Notes: Labels (1) and (6) are the bacilli in the shapes of the word or character. Label (3) is the network structure compose of bacill. Label (7) is cocci. Labels (2), (4) and (5) are algae

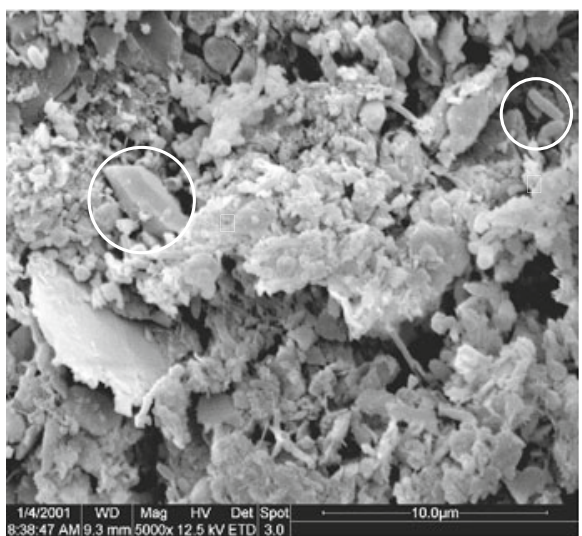

(a) $\operatorname{SLLP}_{\mathrm{A}}(5000 \mathrm{x})$

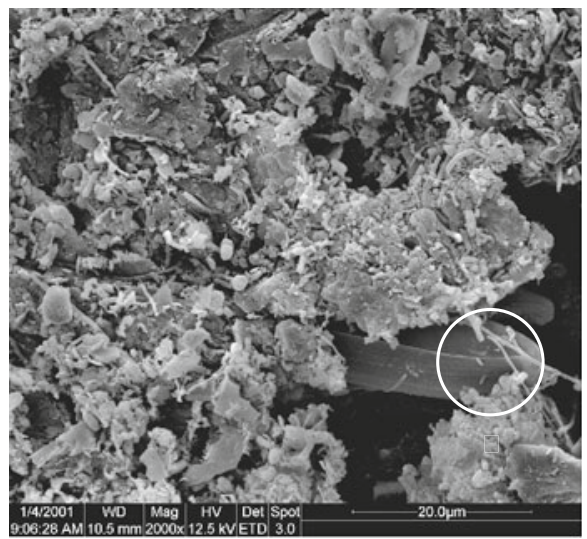

(c) $\operatorname{SLLP}_{\mathrm{C}}(2000 \mathrm{x})$

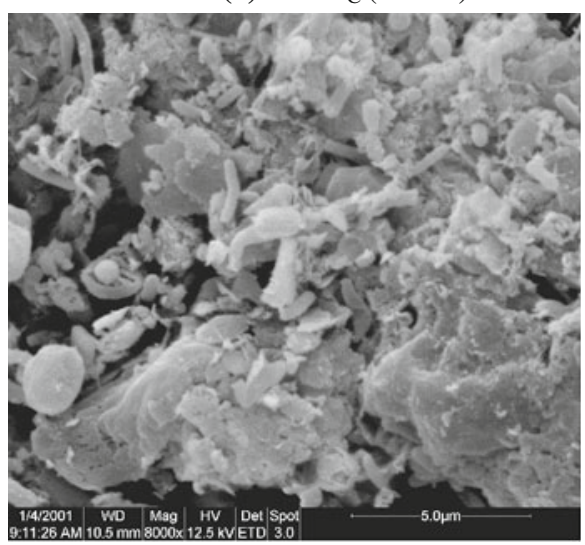

(e) $\operatorname{SLLP}_{\mathrm{C}}(8000 \mathrm{x})$

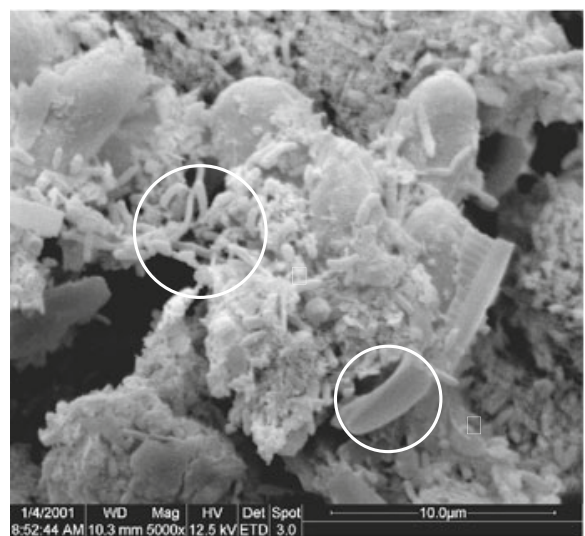

(b) $\operatorname{SLLP}_{\mathrm{B}}(5000 \mathrm{x})$

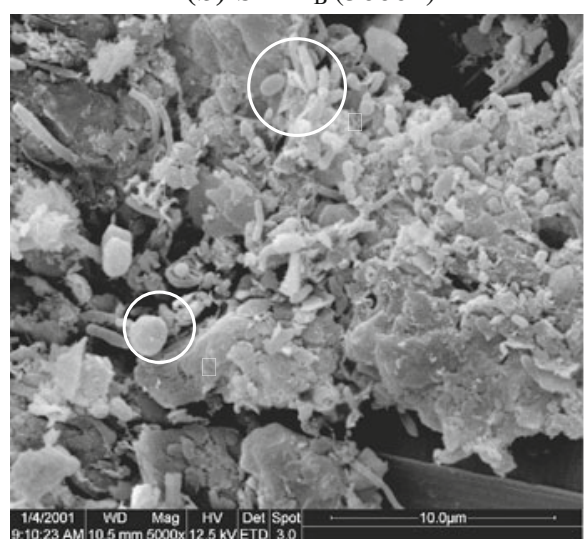

(d) $\operatorname{SLLP}_{\mathrm{C}}(5000 \mathrm{x})$

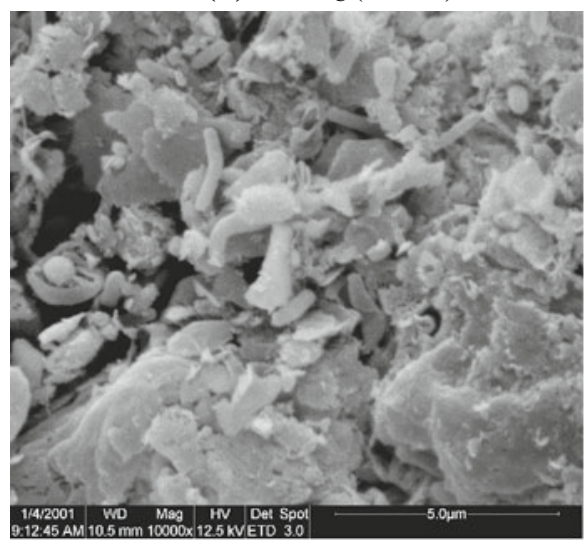

(f) $\operatorname{SLLP}_{\mathrm{C}}(10000 \mathrm{x})$
1.46, respectively (Figs. 6, 7). The differences between the fractal dimensions of biofilms of the same medium surface were little, within $2.8 \%$. And in the other reclaimed wastewater rivers and lakes, the fractal dimensions of the gravel samples was higher than that of aquatic plant samples with the enlargement ratio of $5,000 \times$, with only small differences $(0.2-2.4 \%)$. The difference in fractal dimensions of biofilms surface structures of different samples were also very little, indicating that biofilm characteristics can not be described clearly with simple fractal dimensions. Therefore, a more sensitive parameter, other than simple fractal dimension, is needed to clearly describe the biofilm characteristics.

Multifractal characteristics of biofilm surface structure

The multifractal singular spectra of surface structures were calculated according to previous arithmetic. The calculation contains the following steps: (1) select grid size $\varepsilon$, and calculate the probability measure of each grid; (2) choose 
Fig. 3 SEM images of biofilms on gravel surfaces in Lianshi Lake, Notes: Labe (1) is corynebacterium; Label (2) is coccus

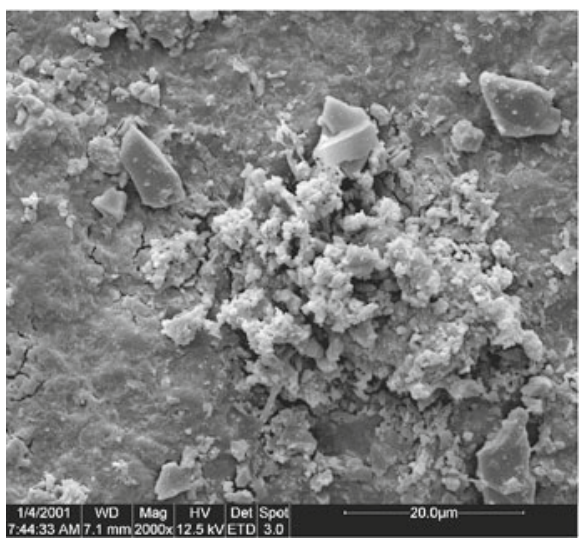

(a) $\operatorname{SLLS}_{\mathrm{A}}(2000 \mathrm{x})$

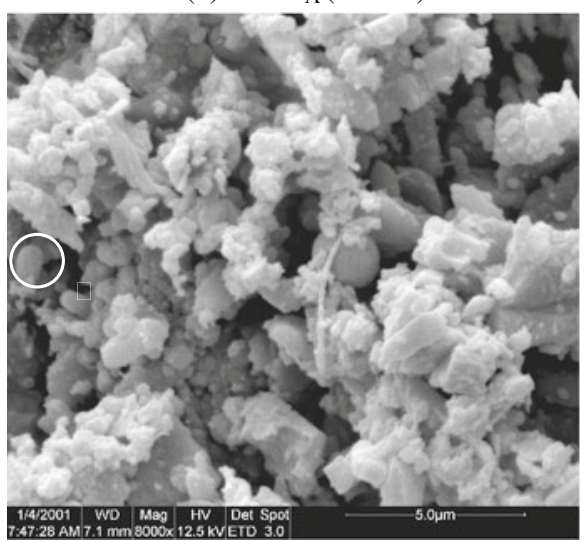

(c) $\operatorname{SLLS}_{\mathrm{A}}(8000 \mathrm{x})$

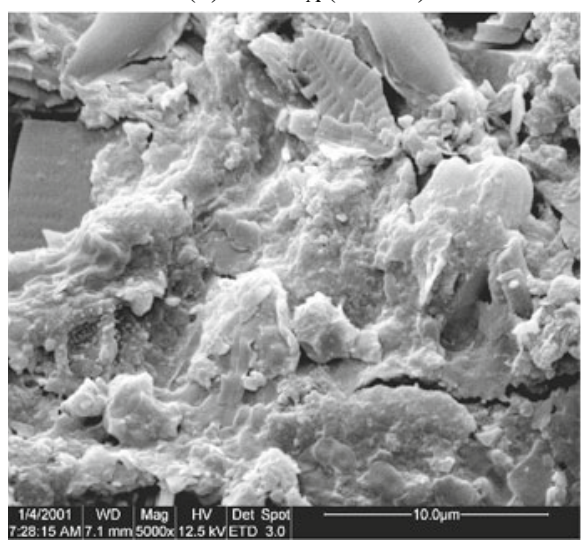

(e) $\operatorname{SLLS}_{B}(5000 x)$

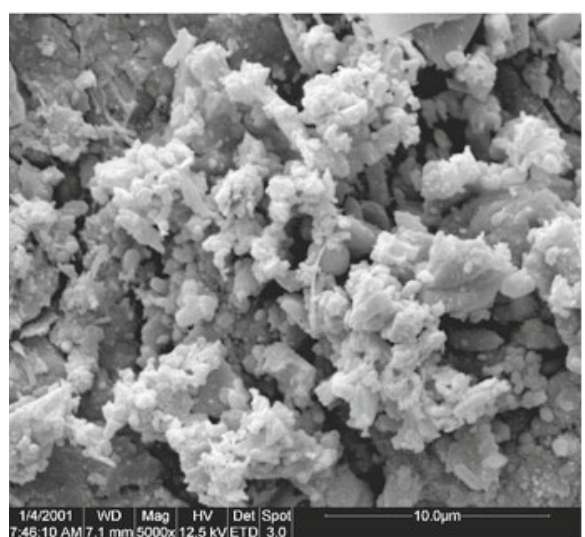

(b) $\operatorname{SLLS}_{\mathrm{A}}(5000 \mathrm{x})$

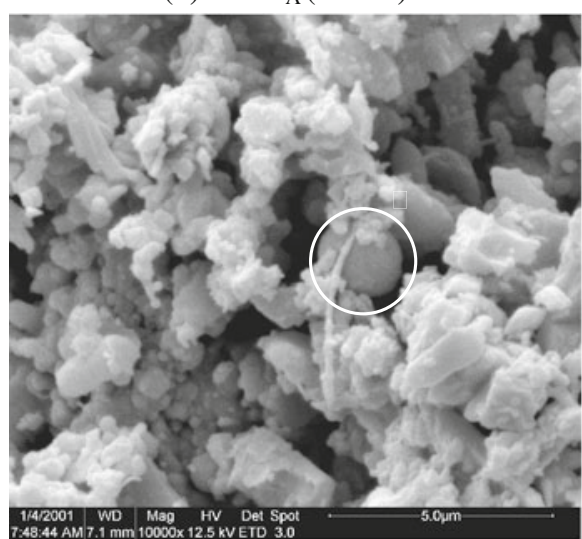

(d) $\operatorname{SLLS}_{\mathrm{A}}(10000 \mathrm{x})$

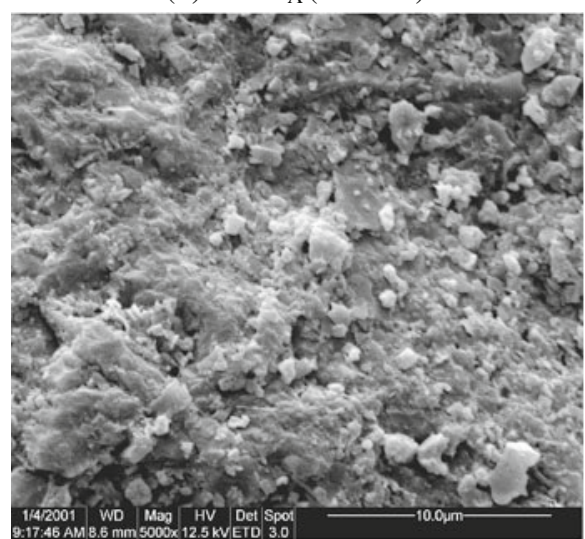

(f) $\operatorname{SLLS}_{\mathrm{C}}(5000 \mathrm{x})$ different $q$ and calculate partition function $\chi_{q}(\varepsilon)$; (3) change the grid size $\varepsilon$ and repeat (1) and (2) to calculate a series of $\chi_{q}(\varepsilon)$; (4) trace the graph of $\ln \left(\chi_{q}(\varepsilon)\right) \sim \ln (\varepsilon)$; (5) calculate $\tau(q)$ for each $q$ by straight line fitting of $\chi_{q}(\varepsilon) \sim \varepsilon$; (6) trace the graph of $\tau(q) \sim q$ and calculate $D(q)$; and (7) calculate $\alpha(q)$ and $f(\alpha)$ with Legendre Transformation and obtain the final multifractal spectrum $\alpha \sim f(\alpha)$. When $10 \leq q \leq 10$ was chosen, the step size was 0.5 ; the grid sizesewere 64, 128, 256, 512 and 1024 pixels, respectively. With the different biofilms as examples, the graphs of $\ln \left(\chi_{q}(\varepsilon)\right) \sim \ln (\varepsilon)$ are shown in Fig. 8 (the example of
Lianshi Lake). The partition functions $\chi_{q}(\varepsilon)$ and $\varepsilon$ had favorable linear correlation in dual-logarithm coordinates. The slope of the straight line was $f(a)$ for the corresponding q. These results indicate that the surface structures of biofilms from both sources had obvious multifractal characteristics.

The shapes of multifractal singular spectrum of surface structure had close correlation with the distribution of surface pore in the biofilms, and the biofilm surface pores also determined the probability distribution. Therefore, the multifractal singular spectrum of surface structure of the 
Fig. 4 SEM images of biofilms on the plant surfaces in reclaimed water, Notes: Labe (1) is the bacilli in the shapes of the character. Labe (2) is cocci, Labe (3) is algae, Labe (4) is the bacilli in the shapes of the word. Labe (5) is moldfungi. Labe (6) is Ring bacteria

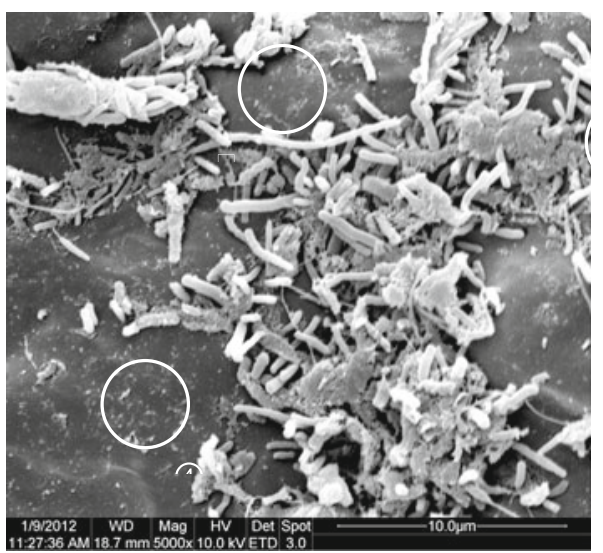

(a) RJRP

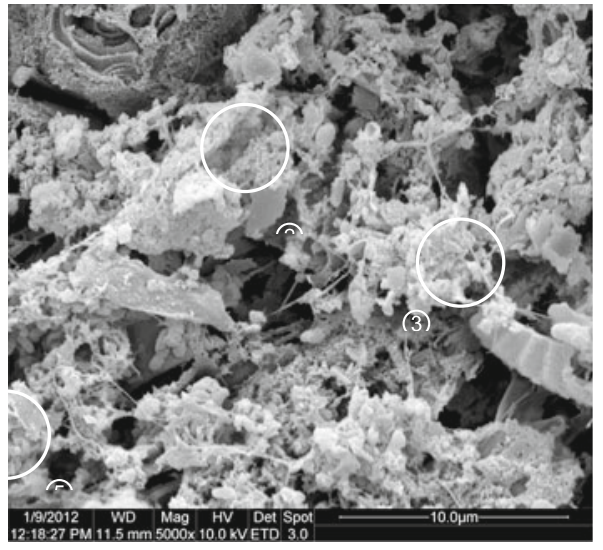

(c) RQRP

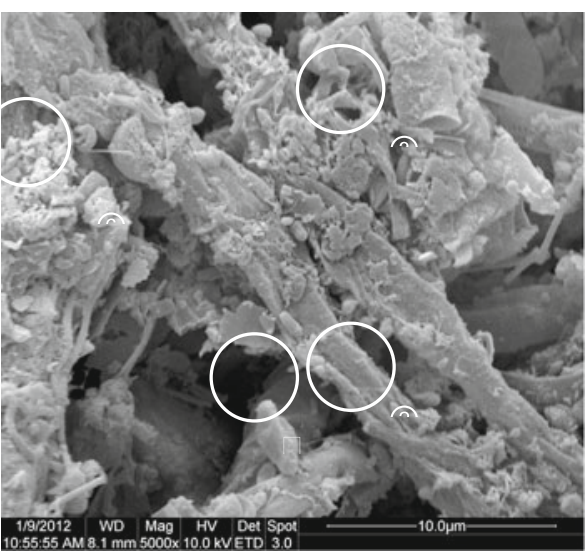

(b) RJLP

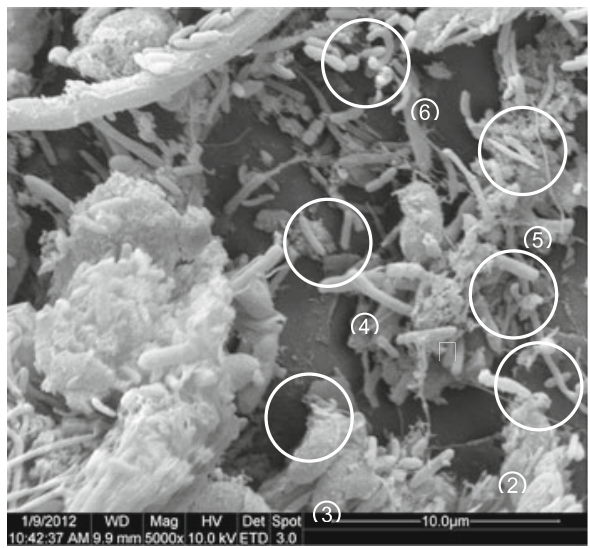

(d) RQLP biofilm from different media and different locations may reflect respective characteristics of probability distribution of pore. The multifractal spectrum $\alpha \sim f(\alpha)$ of surface structure characteristics of biofilms and its important parameters are shown in Fig. 9 and Table 4, respectively. As shown in Fig. 9, the multifractal singular spectrums were all asymmetrical upper convex curves, presenting typical right deviation multifractals, which indicate that most of the pores were small. The $a(q)_{\min }$ and $a(q)_{\max }$ are the variables of singularity indices of the smallest and biggest pore distribution rules with the changes of $\varepsilon$. The smaller $a(q)_{\min }$ is, the bigger the maximum probability $\mu_{i}(\varepsilon)$ will be; and the bigger $a(q)_{\max }$ is, the smaller the minimum probability $\mu_{i}(\varepsilon)$ will be. Thus the span of singularity indexes $\Delta a=a_{\max }-a_{\min }$ can quantitatively describe the degree of heterogeneity of pore distribution probability in biofilms. As shown in Table 4, the structure of biofilms was presented as $\Delta a_{P}>\Delta a_{S}$, suggesting that the heterogeneity of aquatic plants' surface biofilms was higher than that of gravel' surface biofilms. In addition, the structure of biofilms from two sources in Lianshi Lake was presented as $\Delta a_{S L L P}$ and $\Delta a_{S L L S}$ were smaller than others, suggesting that the heterogeneity of biofilms in reclaimed water treated by combined process of deposit and sand filtration and UF membrane filtration plus anaerobic-anoxic-oxic process was higher than that of biofilms in reclaimed water treated by traditionally-activated sludge process (Lianshi Lake's water). The structure of biofilms from the two kinds of reclaimed wastewater was presented as $\Delta a_{R Q}>\Delta a_{R J}$, suggesting that the heterogeneity of biofilms in reclaimed water with the combined process of deposit and sand filtration was higher than that of biofilms in reclaimed water with the UF membrane filtration plus anaerobic-anoxic-oxic process. There is no law about $\Delta a$ between the two kinds of reclaimed wastewater due to the different sewage treatment processes. And the structure of biofilms from the reclaimed wastewater with the combined process of deposit and sand filtration was presented as $\Delta a_{R}>\Delta a_{L}$, the $\Delta a_{R}$ and $\Delta a_{L}$ are almost equal in another reclaimed wastewater. The $f\left(a_{\min }\right)$ and $f\left(a_{\max }\right)$ showed the numbers of pores that were contained in the minimum and maximum subsets of pore distribution probability, thus $\Delta f=$ $f\left(\alpha_{\text {Min }}\right)-f\left(\alpha_{\text {Max }}\right)$ is the number difference between the maximum and minimum probability subsets. When big probability subsets predominate, $\Delta f>0$; when small probability subsets predominate, $\Delta f<0$. All $\Delta f$ were actually larger than 0 (Table 4 ), indicating that the pore 
Fig. 5 SEM images of biofilms on the gravel surfaces in reclaimed water, Notes: Labe (1) is the bacilli in the shapes of the character., Labe (2) is cocci, Labe (3) is algae, Labe (4) ia the bacilli in the shapes of the word

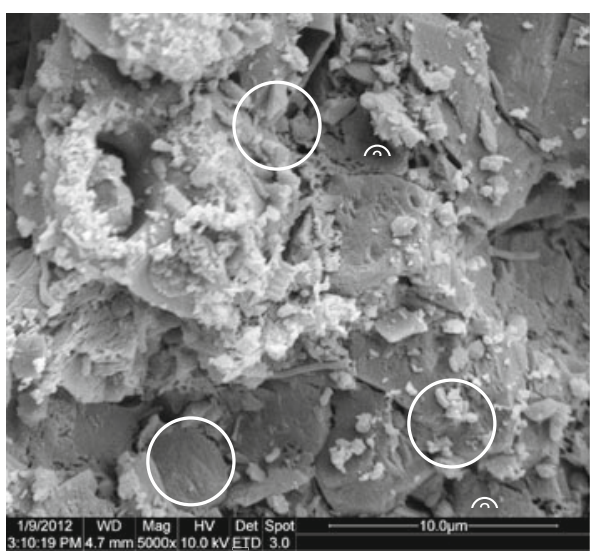

(a) RJRS

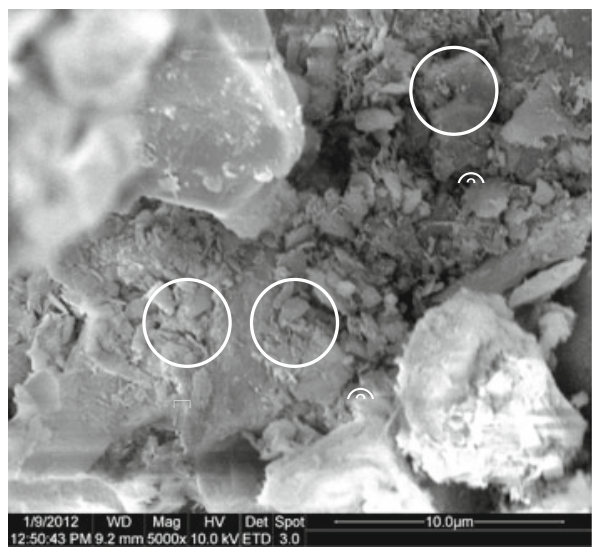

(c) RQRS

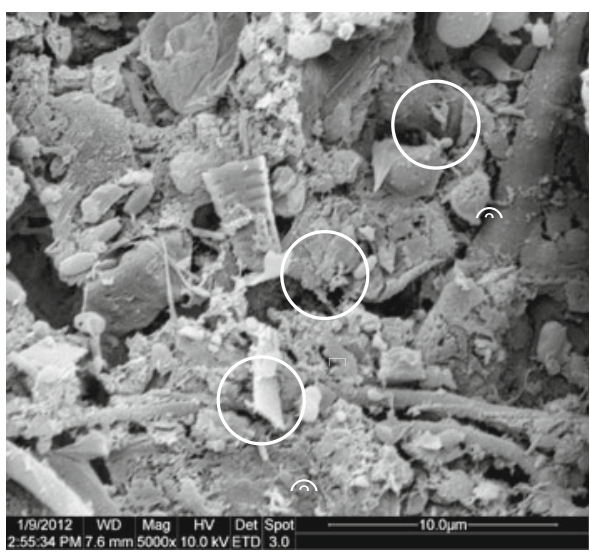

(b) RJLS

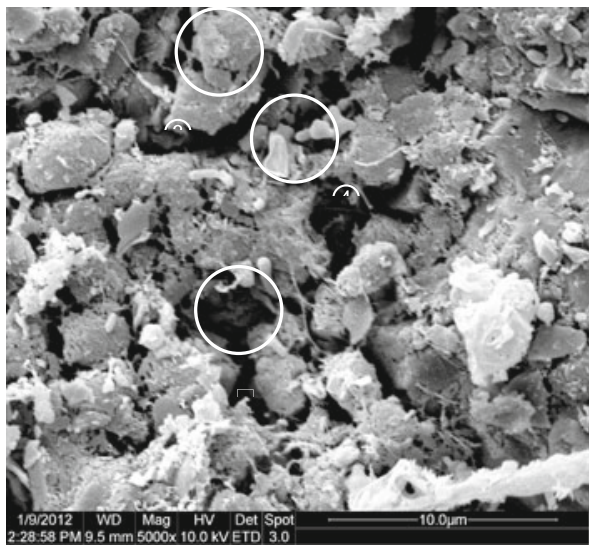

(d) RQLS number in biofilms in subset of maximum pore distribution probability is larger than that in the minimum subset.

\section{Discussion}

Cities are the centers of economic and social development, and water is the lifeblood of the cities. In recent years, urban water consumption and sewage discharge have been dramatically increased along with the rapid economic development. As an important carrier of urban water resources, the river-lake systems have encountered a series of problems, including shrinking lakes, deteriorating water quality, and increasing recession of aquatic ecosystems, which had a serious impact on the improvement of urban functions and the improvements of living standards. Therefore, it is urgent to supply enough ecological water to the river-lake systems. Among the available options, the urban reclaimed wastewater has become an economic and reliable water resource around the world. It has several significant advantages, such as climate-independence, high stability, and local retrievability. Reuse of reclaimed wastewater has become one of the effective measures of the mitigating ecological crisis of rivers and lakes. A large number of application cases have been reported (Fan 2005; Juanico and Friedler 1999). In Beijing, Tianjin, Xi'an, Hefei and other regions of China, a series of successful reclaimed wastewater projects for landscape water usage have been established (Huang et al. 2008). The overall quality of reclaimed wastewater can be accepted by the discharge standards. However, the reclaimed wastewater still contains relatively large amounts of nutritional salts, trace organic pollutants, suspended solid particles and microorganisms, which may significantly affect the riverlake aquatic ecosystems.

The health of aquatic systems can be directly and effectively assessed by monitoring their microorganisms that are the result of comprehensive action with long-term environment evaluation and multi-factor. More than $90 \%$ of microorganisms are living in the form of a biofilm. Biofilms can attach on almost all types of surface exposed in the water in natural environments ( $\mathrm{Li}$ 2005; Mandelbrot et al. Mandelbrot et al. 1984; Posadas et al. Posadas et al. 2003; Chen 2007; Avnimelech 1993), and it is the main interface of chemicals migration and transformation in the environments and plays an extremely important role in the self-purification of river-lake systems. The formation of biofilms is affected by many factors, such as hydrological 
Fig. 6 Fractal dimensions of structure characteristics of aquatic plant surface biofilms (the example of Lianshi Lake)

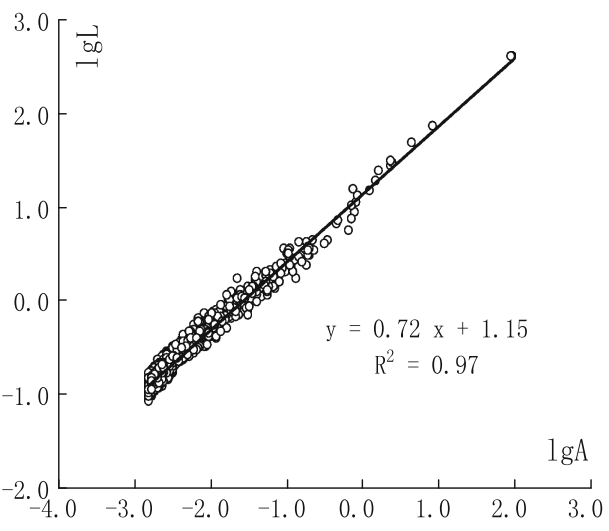

(a) $\operatorname{SLLP}_{\mathrm{A}}(5000 \times)$

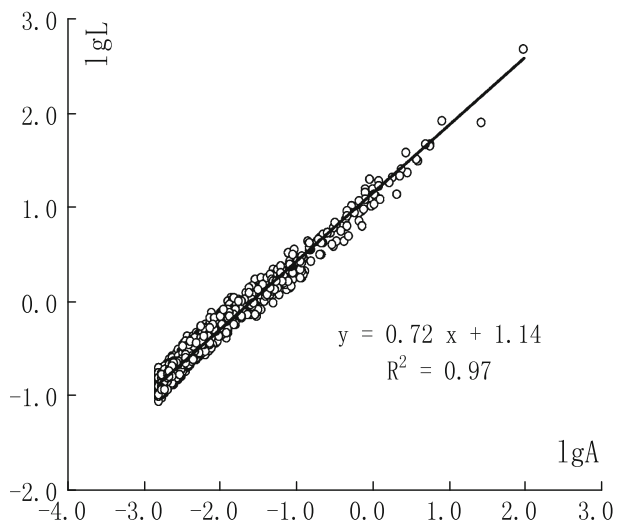

(c) $\operatorname{SLLP}_{\mathrm{C}}(2000 \times)$

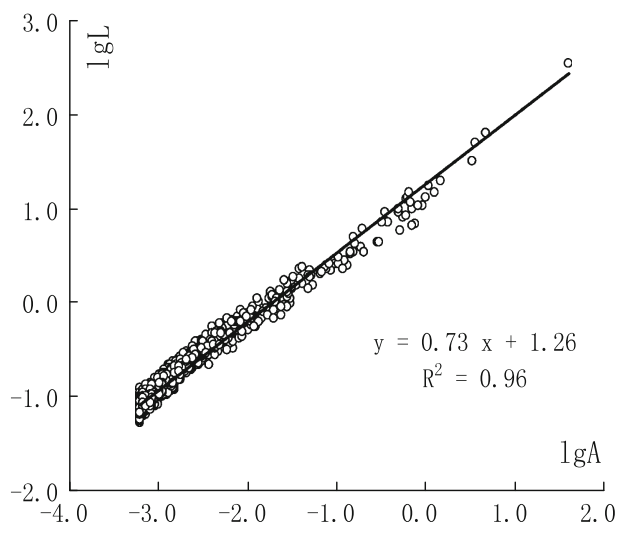

(e) $\operatorname{SLLP}_{\mathrm{C}}(8000 \times)$

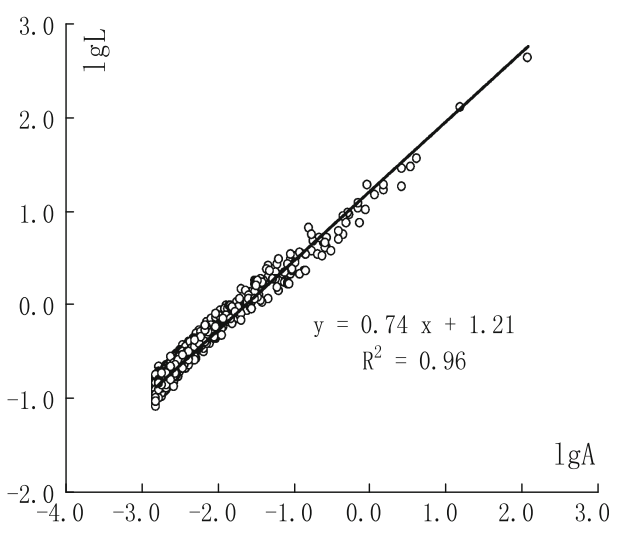

(b) $\operatorname{SLLP}_{\mathrm{B}}(5000 \times)$

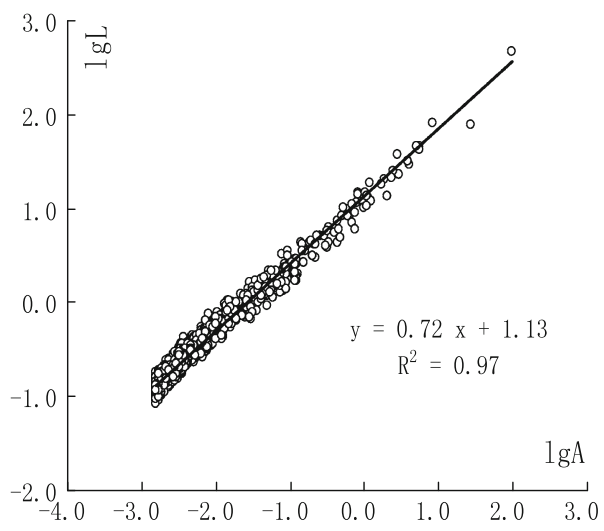

(d) $\operatorname{SLLP}_{\mathrm{C}}(5000 \times)$

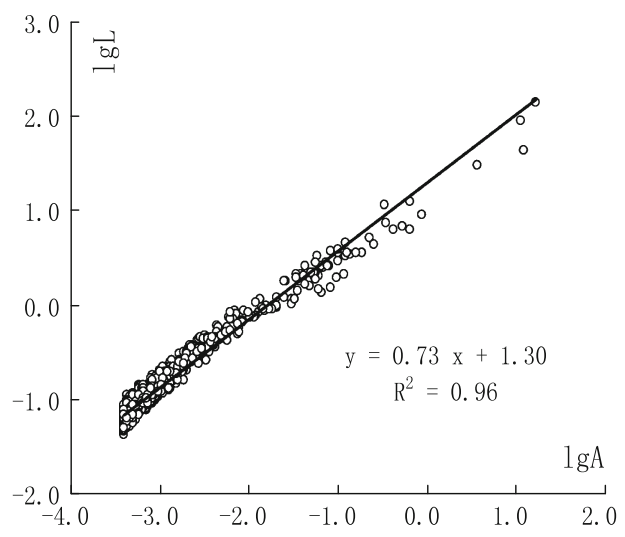

(f) $\operatorname{SLLP}_{\mathrm{C}}(10000 \times)$ conditions, medium types, nutrition levels and light. It has been reported that biofilms with more complex structures are usually formed with higher dissolved oxygen levels, lower water velocity and richer aquatic microbes. There are three major theories on biofilms' morphology and structure (Qin 2008). The first one is the traditional view in which the biofilm is flat homogeneous structure, which was supported by the observation on the plate surface with transmission electron microscopy (TEM). The second is the "heterogeneous mosaic model" proposed by Keevil et al. They observed with differential interference contrast microscope (DIC) that the bacteria and the EPS secreted by these bacteria accumulated into cylindrical structures. The third theory, which is the most accepted, is that biofilm on the support surface is discontinuous and heterogeneous; pores are prevalent in the biofilm and their thickness is unevenly distributed. The biofilms attached on aquatic plants and gravels were between the overlying water and sediment, thus they can synthetically reflect the state of water and sediment. Based on this, the paper investigated the structures of biofilms attached on aquatic plants and gravels in the reclaimed wastewater with SEM in this 
Fig. 7 Fractal dimensions of structure characteristics of gravel surface biofilms (the example of Lianshi Lake)

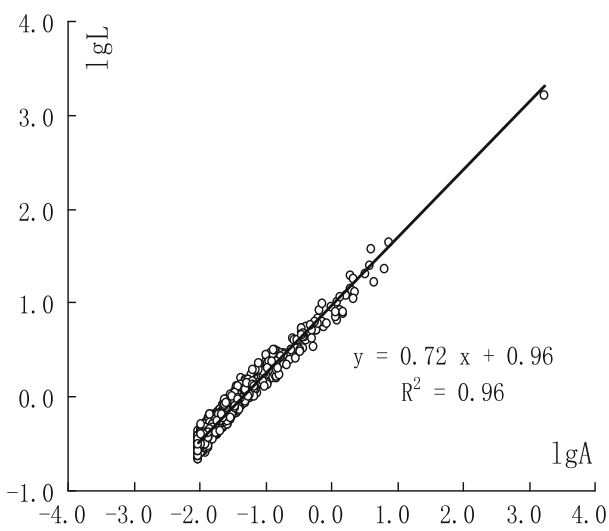

(a) $\operatorname{SLLS}_{\mathrm{A}}(2000 \times)$

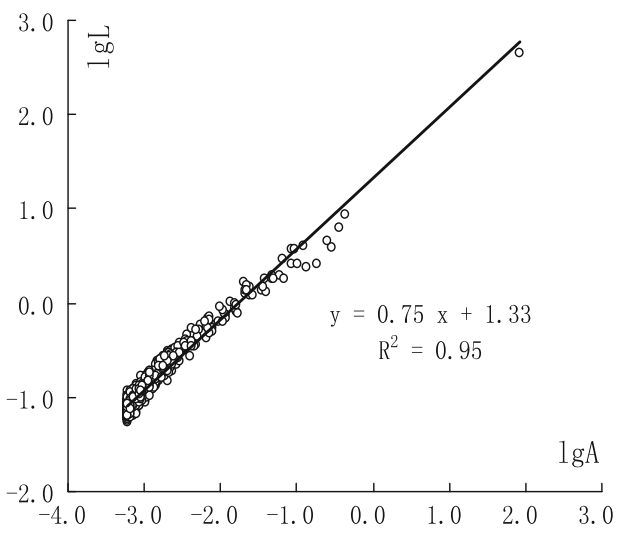

(c) $\operatorname{SLLS}_{\mathrm{A}}(8000 \times)$

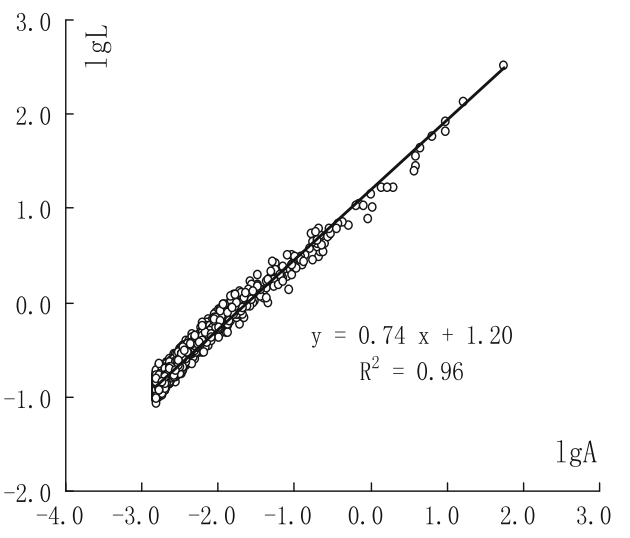

(e) $\operatorname{SLLS}_{\mathrm{B}}(5000 \times)$

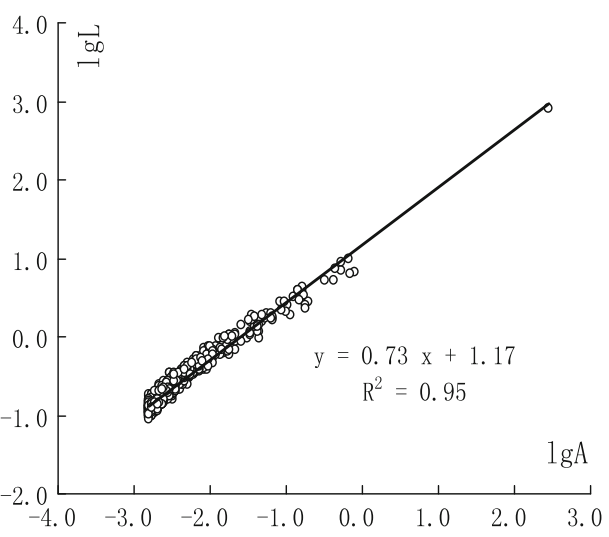

(b) $\operatorname{SLLS}_{\mathrm{A}}(5000 \times)$

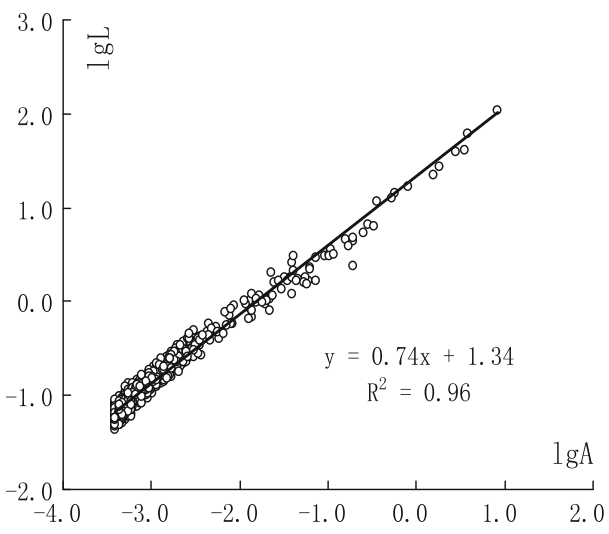

(d) $\operatorname{SLLS}_{\mathrm{A}}(10000 \times)$

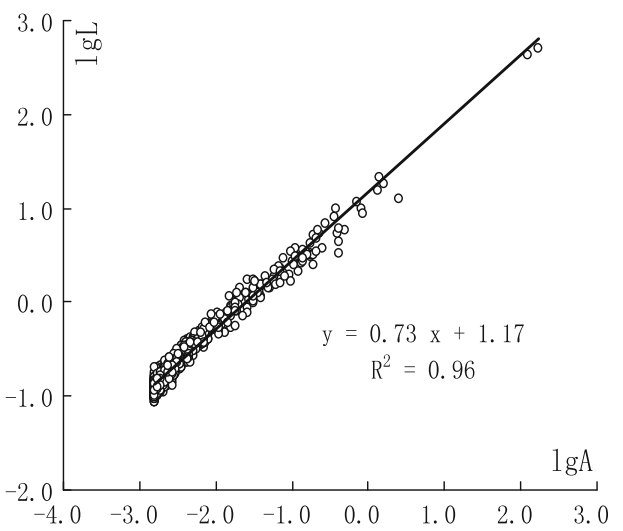

(f) $\operatorname{SLLS}_{\mathrm{C}}(5000 x)$
Table 3 Fractal dimensions of structure characteristics of biofilms

\begin{tabular}{llllll}
\hline Number & $R^{2}$ & $\mathrm{D}$ & Number & $R^{2}$ & $\mathrm{D}$ \\
\hline SLLP & 0.967 & 1.453 & SLLS & 0.957 & 1.467 \\
RJRP & 0.974 & 1.364 & RJRS & 0.970 & 1.398 \\
RJLP & 0.970 & 1.404 & RJLS & 0.971 & 1.410 \\
RQRP & 0.972 & 1.435 & RQRS & 0.970 & 1.438 \\
RQLP & 0.969 & 1.392 & RQLS & 0.973 & 1.402 \\
\hline
\end{tabular}

study. The paper found that both biofilms were typically porous and were composed of rod-shaped and spherical bacteria, algae and inorganic particles. Furthermore, the spaces between the microbial communities were filled with the sticky reticular EPS. Because of the stickiness of EPS, the microbial communities and adsorptions were connected together to form a stable network and heterogeneous porous structure. While the study supports the third theory 


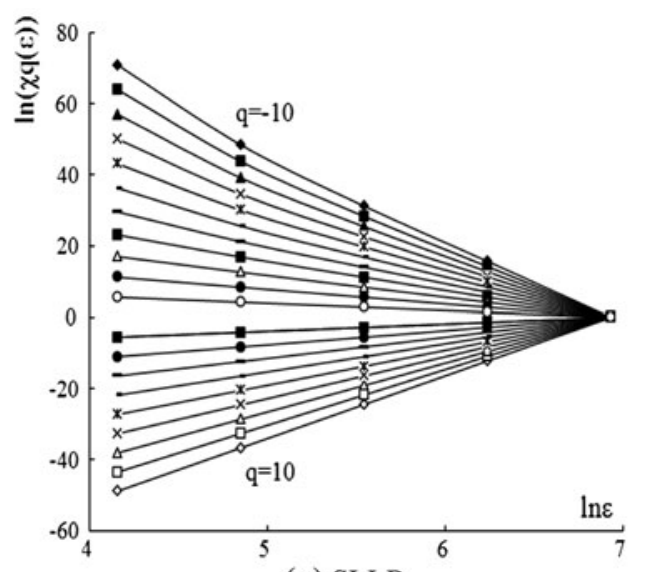

(a) $\mathrm{SLLP}_{\mathrm{C}}$

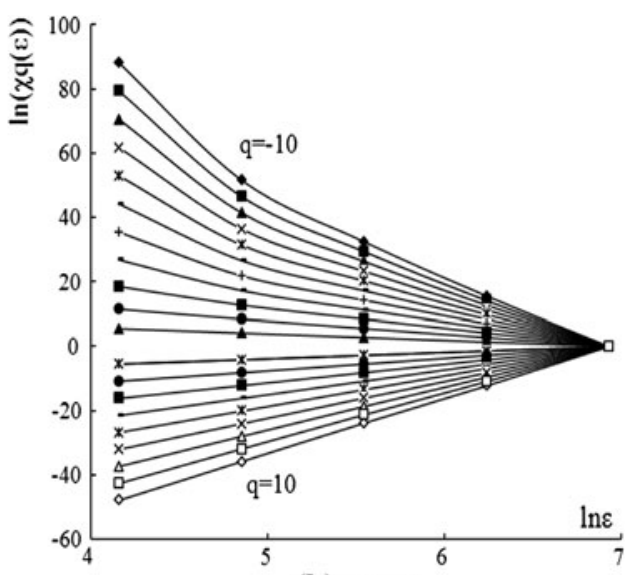

(b) $\mathrm{SLLS}_{\mathrm{A}}$

Fig. 8 The graph of $\ln \left(\chi_{q}(\varepsilon)\right) \sim \ln (\varepsilon)$ of two medium surfaces microbiological biofilm (the example of Lianshi Lake)

described earlier, the biofilms formed in reclaimed wastewater seemed to be more complex than those in natural water (Nelson et al. 1999b; Dong et al. 2002, 2003b).

Since its advent in the 1970s, the Mandelbort fractal theory has become a powerful tool to explore irregular structures and morphologies. A large number of studies have been reported to apply fractal theory applied in describing porous media structure and microscopic morphology characteristics, such as soil and sediment. Therefore, the fractal theory was used to analyze the morphology of biofilms as a porous media (Anderson et al. 1996; Wang and Lu 2005). The study found that the biofilms attached on these two types of surfaces had obvious multifractal characteristics. The fractal dimensions of biofilms from the aquatic plants' surfaces were lower than those from the gravel surface, which was probably due to the effects of light. Furthermore, aquatic plants were closer to the suspended particulates, the attached biofilms grew quickly, and the biofilm particles were also larger. Thus, the adopted particles of biofilms attached on the aquatic plants' surfaces were larger than those of Gravel surfaces. Therefore, the biofilms attached on the aquatic plant surfaces were less complex, similar to the relationship between soil particle size and fractal dimensions in the structures of sand and clay. However, only minor differences in fractal dimensions were observed between the two types of biofilms and among different sample locations (within $2.8 \%$ ), indicating that fractal dimensions alone can not effectively differentiate biofilms. This is not too surprising, considering that fact that many factors are affecting the formation of biofilms. However, simple analysis with fractal dimension was only a self-similar representation of scale stability under average disposal and uniform distribution. And it can characterize the whole complexity and irregularity of biofilms surface characteristics, but it lacks the description of local singularity. As a result, a lot of valuable microcosmic information failed to be revealed. Therefore, a more sensitive parameter was needed to tell one type of biofilm from another.

Multifractal can hierarchically characterize the inner fine structures of substances which provide prominence to the characteristics of abnormal local singularity. In this study, the surface structures of these two biofilms showed obvious multifractal characteristics. The multifractal spectrum reflected the structural differences of biofilms from different surfaces and different sample locations, which indicates that the multifractal can well characterize the complexity of biofilm surface structures. The paper also found that the heterogeneity degrees of biofilms attached on aquatic plants' surfaces were higher than that of biofilms on gravel surfaces. This may be because the surface roughness of aquatic plants was lower than that of the gravel surface, and the portion surface of aquatic plants in water received more light which provided more energy for microbial photosynthesis and growth. Another possible reason is that most of the particles in aquatic plants surface biofilm skeleton were large particles. In addition, the biofilm skeleton had a large number of pore channels that facilitate the transmission and absorption of nutrients and pollutants, which as a result accelerated the microbial decomposition of pollutants. In contrast, the microorganisms on gravel surfaces received less energy, and the dense pore structures were unfavorable to their growth and adsorption of pollutants. Therefore, the biofilms attached on gravel surfaces had lower rates of pollutant degradation and relatively simple structures. In addition, the heterogeneity of biofilms in reclaimed water treated by combined process of deposit and sand filtration and UF membrane filtration plus anaerobic-anoxic-oxic process was higher than that of biofilms in reclaimed water treated by traditionally-activated sludge process (Lianshi Lake's water). As shown in Table 2, the quality of reclaimed wastewater 


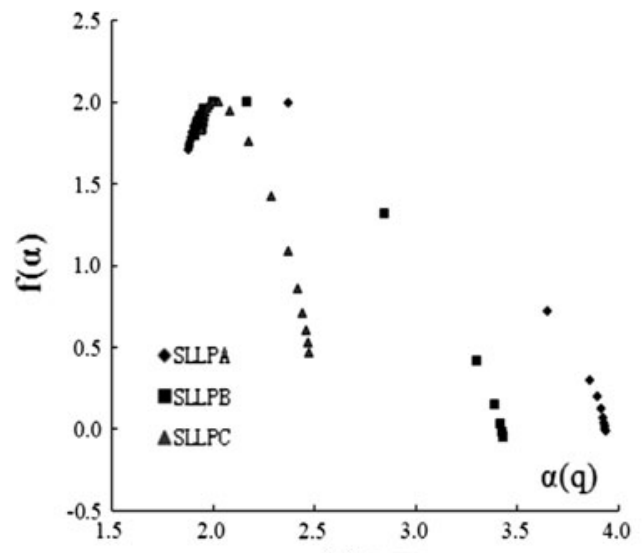

(a) SLLP

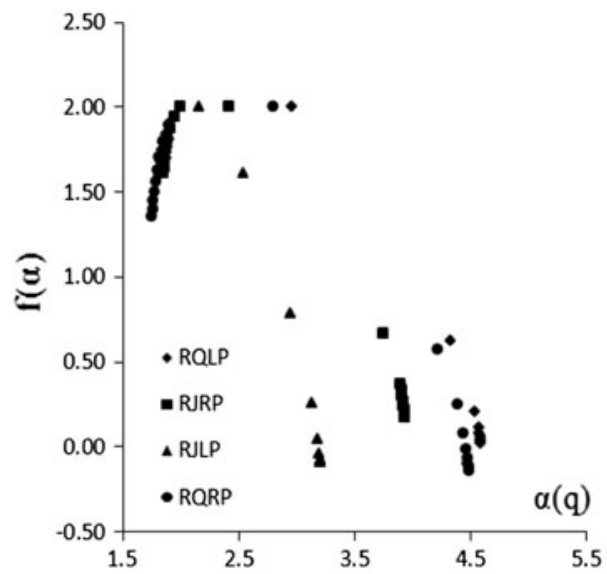

(c) $\mathrm{P}$

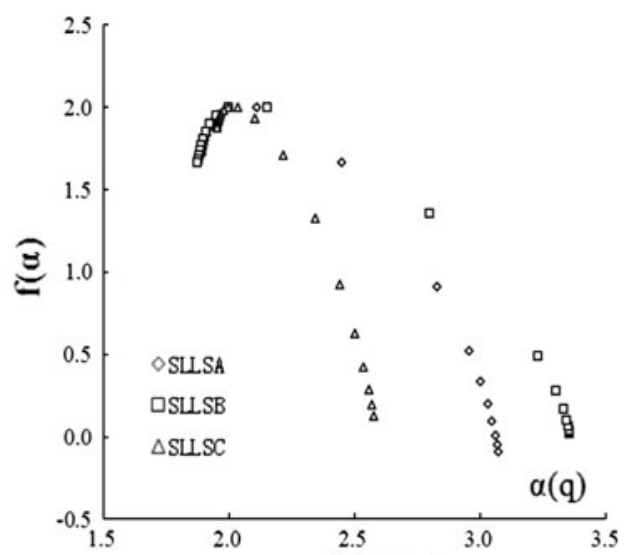

(b) SLLS

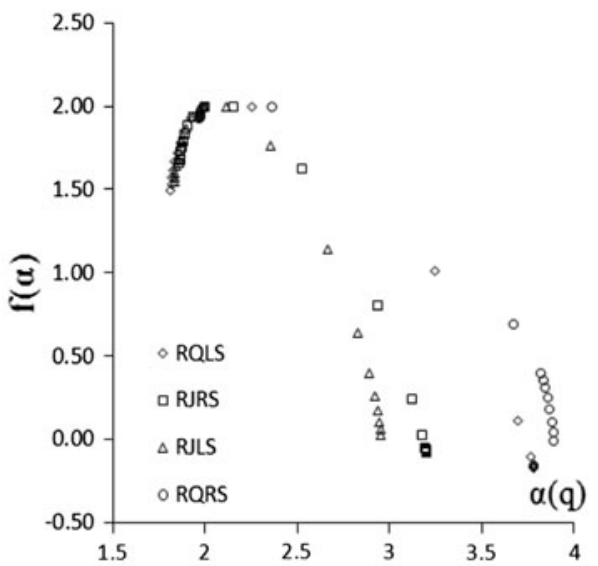

(d) $\mathrm{S}$

Fig. 9 Multifractal spectra of structure characteristics of biofilms from two medium surfaces

Table 4 Important parameters of multifractal spectra of structure characteristics of biofilms

\begin{tabular}{lllllrll}
\hline Sample type & Number & $a(q)_{\min }$ & $a(q)_{\max }$ & $f\left[a(q)_{\min }\right]$ & $f\left[a(q)_{\max }\right]$ & $\Delta a=a_{\max }-a_{\min }$ & $\Delta f=f\left(a_{\min }\right)-f\left(a_{\max }\right)$ \\
\hline Gravel & SLLS $_{\mathrm{A}}$ & 1.892 & 3.071 & 1.713 & -0.090 & 1.179 & 1.803 \\
& SLLS $_{\mathrm{B}}$ & 1.876 & 3.356 & 1.665 & 0.020 & 1.480 & 1.645 \\
& SLLS $_{\mathrm{C}}$ & 1.940 & 2.444 & 1.783 & 0.253 & 0.504 & 1.530 \\
& RJRS & 1.862 & 3.200 & 1.660 & -0.075 & 1.338 & 1.735 \\
Aquatic plants & RJLS & 1.834 & 2.954 & 1.546 & 0.026 & 1.120 & 1.520 \\
& RQRS & 1.972 & 3.893 & 1.927 & -0.006 & 1.921 & 1.933 \\
& RQLS & 1.815 & 3.783 & 1.495 & -0.170 & 1.968 & 1.665 \\
& SLLP & 1.880 & 3.935 & 1.710 & -0.012 & 2.055 & 1.722 \\
& SLLP & 1.910 & 3.433 & 1.795 & -0.053 & 1.523 & 1.848 \\
& SLLP & 1.945 & 2.475 & 1.825 & 0.463 & 0.530 & 1.362 \\
& RJRP & 1.853 & 3.934 & 1.613 & 0.172 & 2.081 & 1.441 \\
& RJLP & 1.863 & 3.206 & 1.645 & -0.087 & 1.343 & 1.732 \\
& RQRP & 1.755 & 4.484 & 1.358 & -0.140 & 2.729 & 1.498 \\
& RQLP & 1.820 & 4.587 & 1.593 & 0.022 & 2.767 & \\
\hline
\end{tabular}

differs greatly because of the different processes. The combined process of deposit and sand filtration can improve the clearance rates of $\mathrm{BOD}$ and $\mathrm{COD}$ only up to
$60 \%$ and UF membrane filtration plus anaerobic-anoxicoxic process can result in a removal rate of more than $80 \%$ for $\mathrm{BOD}$, the clearance rate of $\mathrm{BOD}$ of traditionally 
activated sludge process was 90-95\% (Gan et al. 2010). There are still more nutrients and pollutants in the two kinds of reclaimed water than in Lianshi Lake's water. So the two kinds of reclaimed water can provide enough nutrients for microorganisms. Thus, there are much more microorganisms in the two kinds of reclaimed water than in Lianshi Lake's water. And the microorganisms are the biological basis of biofilms. Therefore, the biofilms in the two kinds of reclaimed water had more complex structures than that in Lianshi Lake's water. Besides, the heterogeneity of biofilms in reclaimed water treated by combined process of deposit and sand filtration was higher than that of biofilms in reclaimed water treated by UF membrane filtration plus anaerobic-anoxic-oxic process.

In summary, the paper investigated the structures and the fractal characteristics of biofilms attached on the surfaces of aquatic plants and Gravels in reclaimed wastewater lake using SEM technology and fractal theory, and obtained several significant discoveries. The following future directions will certainly strengthen what the study has achieved:

(1) Comprehensive application of modern fine microscopy and molecular biology to establish better methods to quantitatively characterize the formation and structure of biofilms attached to the multiple medium surfaces in river-lake systems using reclaimed wastewater;

(2) Biofilm characteristics were analyzed with in situ sampling method in this study, which may be affected in the differences of background values. Therefore, different roughness of artificial substrates will be used to extract biofilms, in order to systematically study the formation process, the shape and community structure characteristics of multiple medium surface of biofilms, and to study the behavior of biofilm on adsorption and degradation of pollutants;

(3) Comprehensive analyses of biofilm formation, structure and the chemical behaviors of water environments to better employ the potential of biofilms in monitoring and evaluating the health of river-lake ecological systems.

\section{Conclusions}

The biofilms attached on the surfaces of aquatic plants and gravels were both typical porous media. Their skeletons were composed of inorganic particles, microorganisms, and algae. Most spaces between the particles were filled with EPS secreted by the bacteria, which formed the complex and stable biofilm structures. These two types of biofilms showed obvious fractal characteristics. However, the differences in fractal dimensions were very small between these two types of medium surfaces and among different sampling locations. Therefore, fractal dimensions alone can not well characterize the biofilm differences. The multifractal spectrum was able to quantitatively characterize the heterogeneity of biofilm surface structures. Furthermore, the microbial species, quantity, and the heterogeneity of biofilms attached on aquatic plant surfaces were higher than those on gravel surfaces, mainly because of the effects of light. At the same time, the particulates of biofilms on aquatic plant surfaces were relatively larger and looser than those on gravel surfaces. In addition, the heterogeneity of biofilms in reclaimed water treated by combinatorial process of deposit and sand filtration and UF membrane filtration plus anaerobic-anoxicoxic process was higher than that of biofilms in reclaimed water treated by traditionally activated sludge process (Lianshi Lake's water). Besides, the heterogeneity of biofilms in reclaimed water treated by combinatorial process of deposit and sand filtration was higher than that of biofilms in reclaimed water treated by UF membrane filtration plus anaerobic-anoxic-oxic process.

Acknowledgments We are grateful for the financial supports from the Key Project of Beijing Eleventh-Five Year Research Program (No. D090409004009004), the Special Fund for Water Conservancy Scientific Research in the Public Interest (201001067) and the Program for New Century Excellent Talents in University (NETC-100780).

\section{References}

Anderson AN, Mcbratney AB, Fitz Patriek EA (1996) Soil Mass, Surface, and Spectral Fractal Dimensions Estimated from Thin Section Photograph [J]. Soil Sci Soc Am J 60:962-969

Avnimelech Y (1993) Irrigation with effluents: the Israeli experience [J]. Environ Sci Technol 27(7):1278-1281

Baloch MI, Akunna JC, Kierans M, Collier PJ (2008) Structural analysis of anaerobic granules in a phase separated reactor by electron microscopy [J]. Bioresour Technol 99(5):922-929

Baty AM (1996) Adhesion of bioflims to insert surfaces: A molecular level approach directed at the marine environment [J]. Biofouling 10(1-3):111-121

Chen S (2007) Characteristics and efficiency investigation of suspended carrier biofilm for treating highly concentrated organic wastewater. $\mathrm{PhD}$ thesis, Harbin Institute of Technology

Costerton JW, Stewat PS, Greenberg EP (1999) Bacterial Biofilms: A Common Cause of Persistent Infections [J]. Science 284:1318

Dong DM, Hua XY, Li Y, Li ZH (2002) Lead adsorption to metal oxides and organic material of freshwater surface coatings determined using a novel selective extraction method [J]. Environ Pollut 119(3):317-321

Dong DM, Hua XY, Li Y, Zhang JJ, Yan DX (2003) Cd adsorption properties of components in different freshwater surface coatings: the important role of ferromanganese oxides [J]. Environ Sci Technol 37(18):4106-4112

Dong DM, Yang F, Li Y, Hua XY, Lü XJ, Zhang JJ (2005) Adsorption of $\mathrm{Pb}, \mathrm{Cd}$ to $\mathrm{Fe}, \mathrm{Mn}$ oxides in natural freshwater surface coatings developed in different seasons [J]. J Environ Sci 17(1):30-36 
Fan QK, Lv WY (2005) Preliminary study on reusing the regenerated wastewater to landscape water [J]. Environ Sci 31(130):28-30

Gan YP, Bai Y (2010) The depth of the sewage treatment plant and recycling technology. China Arch Build Press 7(1):198-314

Huang JP, Wu LY (2008) Standard implementation guide for urban sewage recycling. Standards Press of China, Beijing

Juanico M, Friedler E (1999) Wastewater reuse for river recover in semiarid Israel [J]. Water Sci Technol 40:43-50

Li J (2005) Studies on characteristics and function of biofilms in the constructed wetland and urban water bodies. $\mathrm{PhD}$ thesis, Institute of Hydrobiology, the Chinese Academy of Sciences

Li GB, Li YK, Xu TW, Liu YZ, Jin H, Yang PL, Yan DZ, Ren SM, Tian ZF (2011) Effects of average velocity on the growth and surface topography of biofilms attached to the reclaimed wastewater drip irrigation system laterals [J]. Irrigation Science. doi:10.1007/s00271-011-0266-4

Mandelbrot BB, Passoja DE, Paullay AJ (1984) Fractal character of fracture surface of metals [J]. Nature 308(19):721-723

Nelson YW, Lion LW, Shuler ML, Ghiorse WC (1999) Lead binding to metal oxide and organic phases of natural aquatic biofilms. Limnol Oceanogr 44(7):1715-1729

Percival SL, Knapp JS, Edyvean R, Wales DS (1998) Biofilm development on stainless steel in mains water [J]. Water Res 32(1):243-253

Picioreanu C, van Loodrecht MCM, Heijnen JJ (2001) Two-dimensional model of bioflim detachment caused by internal stress from liquid flow [J]. Biotechnol Bioeng 72:205-218

Posadas AND, Giménez D, Quiroz R, Richard P (2003) Multifractal characterization of soil pore system $[\mathrm{J}]$. Soil Sci Soc Am J 67:1361-1369
Qin SY, 2008. Study on morphology and biodiversity of biofilm of river oder. PhD thesis, Harbin Institute of Technology

Rao TS (1997) Biofilm formation in a freshwater environment under photic and aphotic conditions [J]. Biofouling 11(4):265-282

Reichert P, Wanner O (1997) Movement of solids in biofilms: significance of liquid phase transport [J]. Water Sci Technol 36(1):321-328

Schorer M, Eicele M (1997) Accumulation of inorganic and organic pollutants by biofilm in the aquatic environment [J]. Water Air Soil Poll 99:651-659

Sergi S, Helena G, Anna R, Isabel M (2002) The effect biological factors on the efficiency of river bioflims in improving water quality [J]. Hydrobiologia 469:149-156

Tatlor GT (1997) Influence of surface properties on accumulation of conditioning flims and marine bacterial on substrata exposed to oligotrophic water [J]. Biofouling 11(1):31-57

Wang YL, Lu JJ (2005) The fractal characteristics research of sediment particle surface fractal [J]. J Environ Sci 25(4): 457-463

Wang RC, Wen XH, Qian Y (2003) The biofilm research with Laser Scanning Confocal Microscope [J]. China Water Wastewater 19(12):23-25

Wei Fusheng (2002) Water and exhausted water monitoring analysis method, China Environmental Science Press. ISBN 7-80163400-4

Winpenny J (1996) Ecological Determinants of Bioflim Formation [J]. Biofouling 10:43-63 